\title{
Sustainability in IS: The Case for an Open Systems Approach
}

\author{
Peter M. Bednar ${ }^{1}$ and Christine Welch ${ }^{2}$ \\ ${ }^{1}$ School of Computing, University of Portsmouth, UK \\ ${ }^{2}$ Dept. Strategy \& Business Systems, University of Portsmouth, UK \\ \{peter.bednar, christine.welch\} @port.ac.uk
}

\begin{abstract}
Common sense tells us that cost cutting leads to saving, and spending should therefore be minimized. However, a little reflection tells us that this sometimes leads to false economies. In an organizational context, these can lead on to a downward spiral of organizational 'suicide'. Examples of false economies may include: saving on maintenance; saving on research and development expenditure; saving on margins (waste or just-in-time management); and saving on 'how' we do things, as opposed to 'what' we do. Common sense cost cutting makes 'how' invisible, and only recognizes 'what'. It is vital that we also remember to consider 'why' activities are undertaken. Professional competence implies not only skill/knowledge in a particular field, but also desire to apply that knowledge in accordance with certain values, and engagement with the context of application so that learning through reflection may take place. Professional work therefore includes scope for extra-role behaviour, such as suggesting innovative methods or identifying and developing new opportunities (Bednar and Welch, 2010). We suggest that a naïve pursuit of 'efficiency' is likely to constrict and curtail possibilities for extra-role behaviour, with disastrous consequences for the development and growth of the business. Creation of systems experienced as sustainable therefore requires us to focus attention on perceived usefulness, rather than efficiency.
\end{abstract}

Keywords: Contextual Analysis, Open Systems Approach, Contextual Dependency, Socio-Technical Design, Complex Information Systems.

\section{Background}

It is possible to conceive of an organization as a particular instance of a purposeful human activity system (Checkland, 1981). A precise agreement about the nature of that system would be difficult to achieve since individual experiences of the same phenomenon vary widely. Boundaries drawn by a person in conceiving of a human activity system will depend upon her changing perspectives over time, which are unlikely to concur precisely with those of others. Organisations subsist as complex, open systems that are continually co-created and recreated through the interactions between their individual members. Open systems that we experience as useful involve a certain ambiguity - a tolerance for variations and imperfections. Maintenance of a perfect equilibrium at all times would be both impossible, in the light of individual, 
contextually-dependent interpretations of system boundaries. This is, in essence, the reason why Vickers (1972), for instance, preferred a model of relationship maintaining to one of goal seeking when he reflected upon the nature of organizational management. ICTs are deployed in a purposive, contextuallydependent way, i.e. relevant to some particular members of the organization who expect to engage with them in their work. The information needs of those individuals will be recreated continuously over time in the context of activity. Use of the data system will therefore need to be adaptive to these needs. Attempts to design perfect equilibria in such systems would be likely therefore to have an adverse effect on usefulness in practice.

Recently an insurance company perceived a problem in their order processing system, resulting in a significant decline in customer satisfaction. In response, a new IT system was developed early in 2010 intended to improve productivity by enabling each operator to answer four calls simultaneously, together with on-line ordering and a facility for customers to look up product information for themselves. Statistics covering the following year showed an increase in customer inquiries answered. However, the number of actual orders placed remained remarkably constant throughout the period of the project. The impact of the new system was marginal on productivity, but customer satisfaction continued to decline drastically throughout the period measured. However, the exponents of the new system continued to assert its vaunted benefits - these were, they implied, still hidden in undiscovered and unspecified 'qualitative' data. This appears to be an instance of a solution looking for a problem - an assumption that whatever difficulties the order processing system was experiencing, the answer must surely be a new piece of software. The lack of any evidence of progress was then disqualified by the evaluators themselves with the suggestion that they simply had not looked for it in the right place. This case reminds us of work by Williams (2007) reporting research by the IT Governance Institute into 1600 projects in UK businesses. More than half of these projects in organizations were seen to deliver only marginal benefits, but in approximately one third of cases projects actually destroyed organizational value. He also puts forward evidence to suggest that managers continue to support these projects beyond the point where they already know that this will happen.

Why this apparent paradox? We suggest that it is the undue focus on the 'what' (e.g. "functional requirements") of system developments, as opposed to the 'how' (e.g. "non-functional requirements"). Managers simply say to themselves that the initiative must deliver value (according to common sense logic). We suggest that this phenomenon is caused by a fragmented view of the development process, brought about by a lack of a sound and holistic socio-technical approach to systems analysis. Although analysts may recognise the importance of a socio-technical stance, taking into account context, this is frequently limited to local context. Analysis is then restricted by a closed systems perspective (focusing on 'what' a system is intended to do) but sustainability in IS depends upon an open systems perspective (including 'how' and why a system may be experienced as useful by someone). Managing effective transfer and diffusion of technologies requires consideration of the wider environment within which a company is operating and not just its own, internal technical systems. 


\section{Problem Space}

Langefors (1966) pointed out that those engaged in managing an organization need to know about the behaviour and condition of all its component elements, and the wider environment in which it operates at any given time. It is possible to develop a data system to support managers in their tasks, which becomes an information system for any given individual through direct and interpretive participation. Langefors originally considered that the purpose of an information system was to promote attainment of organizational goals. However, he soon realised that expression of any such goals was itself a problematic task, itself requiring a supporting information system. A reflexive relationship can therefore be seen between these defined purposes of IS: promoting the attainment of organizational goals and also support for goal setting. Viewed as a human activity system, the elements of an organization are all interrelated - operational units, sub-systems to monitor their operations and a managing sub-system interpreting data from them, in order to support operations with appropriate resources and directions. Since these interrelated elements are coordinated through interconnected information-generating units, it may be preferable to view the organization and its information system as different views of the same phenomenon (Langefors, 1995, p53).

Consideration of sustainability in information systems requires us to pay further attention to the nature of organisations. A system may be described as autopoietic (self re-creating) if its component parts interact with each other so as to continually [re] produce and maintain that set of components and the relationships between them (Maturana and Varela (1980, pp. 78-79). There must be sub-systems perceived to be allopoietic, i.e. that have a purpose other than continuation of their own integrity. Luhmann (1990 in Midgley, 2003 p.67)) has suggested by analogy that social systems, such as organisations, can be seen as autopoietic within a given boundary, i.e .a homeostatic, self-referential system whose critical variable is its own existence not, of course, living, conscious beings. It is not 'life' that is continually [re]produced but 'meaning'. Such a system constantly creates and recreates itself within its autopoietic space in the context of interactions with its environment. Any structural element of the system may change radically over time, but the existence of the system is maintained. Within the context of an organisation, the elements of which it is comprised may be observed as allopoietic sub-systems, i.e. their interactions make up inputs and outputs to organisational processes and are therefore purposeful in that organisational context. An organisation is part of the wider environment with which the individual system must interact in maintaining its ontological integrity - the sole ultimate goal of an autopoietic system. It is interesting to reflect upon this in comparison with Vickers' idea of organisational management systems as relationship maintaining, rather than goal seeking. If the theory of Autopoiesis is accepted, then the goals of the disparate elements cannot be identical, or congruent with the expressed goals of the wider organizational system, at any given time.

There have been examples of companies which thrive in the initial stages of marketing a new product, while the market is expanding. However, once the market nears saturation point, the initial success is not sustained because the company is too product-oriented (and confuses usability with usefulness). Customers do not necessarily choose products on their technical specifications alone, but on a whole 
range of 'qualities' influenced by convenience, fashion and availability. An example can be found in the experience of Nokia during 2010 leading to total restructuring of its mobile business 2011 (Orlowski, 2011). The need for an ecological approach is illustrated by Capra (1996) who discusses the example of a bicycle perceived as a system. An ecological awareness goes beyond perceptions of the cycle as personal transport, to consider its natural/social environments. This incorporates awareness of the materials from which it is made; the sources of those materials and the processes by which they were derived; how and where the bicycle was designed, manufactured and marketed; what potential riders are seeking for in their use of the bicycle; its impact on the environment in which it is ridden and the society in which the riders live, and so on.

When a business wishes to deal with losses or to increase profits, there are two alternatives: reduce costs or increase revenue streams. The first alternative is clearly a good idea if there is a lot of wasteful inefficiency in the firm, e.g. a lot of wastage in the production process or poor management of administrative functions. However, great care is necessary because cuts to essential services can be counter-productive. For example, suppose the Board of a company look around for areas to cut costs and see the R\&D department as a drain on resources. They may choose to cut the research budget, with the result that the firm does not develop or apply relevant technology, notice a new development in technologies, or a change in customer tastes. The rival firm in the next town, which still has its $R \& D$ department fully functioning, may well notice these trends and respond to them effectively, thus taking away some of the cost cutters' market share. This will lead to a fall in that firm's existing revenue streams i.e. reduction in profit. In effect, the business is shrinking. It is possible to view this in systemic terms as an instance of a positive feedback loop having a destructive effect on system behaviour. The action taken in the firm to bring output in line with expectations has actually had the opposite effect and the discrepancy between planned and actual output increases (See Schoderbek, et al 1990, pp112-113). In the 1970's and 1980's, when 'new technologies' were first given serious consideration in business organizations, much emphasis was on cost savings. This is quite logical: one word processor operator could achieve the same work output as several typists. Similarly, if a production line can be 'manned' by software controlled robots, there are savings in wage costs - particularly as robots do not take sick leave or need holidays. Thus, a dominant idea grew that ICTs are a means of saving on costs. Of course, considerable investment in new systems was needed in order to attain these desirable savings. The difference between costs and investment is an important one and must always be borne in mind by those spending organizational budgets. The Law of Diminishing Returns in classical economics tells us that, as investment in capital increases, so the marginal increase in revenue diminishes (Samuelson and Nordhaus, 2009). In a similar way, the extent to which investment in ICTs can deliver efficiency gains will be limited. Especially if the necessary investment in the organisational development, behaviour and change-process is ignored, underestimated or not understood. The emphasis on efficiency gains also ignores the important role of ICT investment in improving effectiveness. Often, these systems are enablers of progress (or sometimes just keeping up with the on-going needs of users for enhanced utility). 


\section{Conclusion}

Developments in ICTs have not focused just upon efficiency. We have faster machines and smarter software systems than those of the 1980's. No bricks-andmortar bookshop of the 1980's could have carried out the kind of analytics on customer purchasing behaviour that Amazon.com is able to do today. Profits can be increased not through efficiencies but through change of organizational behaviour and thus generation of enhanced and new revenue streams. However sustainable effectiveness is a sociotechnical phenomenon requiring a focus not on technology dissemination, usability and potential use - but on contextually relevant application and usefulness. Traditional socio-technical approaches (e.g. Mumford, 1983) do not go far enough in promoting systems experienced as useable in context. Methods are required that are based in phenomenology, to address complex open systems by providing support for inquiry into multiple levels of contextual dependencies (e.g. Bednar, 2000). Sustainability in business requires understanding of the (complex) relationship between investment, cost control and profitability. Leaders and "visionaries" often engage in rhetoric suggesting that their policies will simultaneously achieve cost savings and improvements in quality. It is necessary to be sceptical about such claims however and challenge paradoxical thinking which leads to creation of IS that are not only not perceived as useful by organizational actors, but which can actually destroy value for the business.

\section{References}

Bednar, P.: A Contextual Integration of Individual and Organizational Learning Perspectives as Part of IS Analysis. Informing Science 3(3), 145-156 (2000)

Bednar, P., Welch, C.: Professional desire, competence and engagement in IS context. In: D'Atri, A., de Marco, M. (eds.) Management in the Interconnected World: Exploring the Connection between Organizations and Technology, pp. 359-366. Springer, Heidelberg (2010)

Capra, F.: The Web of Life: A new scientific understanding of living systems. Anchor Books, NY (1996)

Grant, I.: India deal clears Skandia's app maintenance backlog. Computer Weekly, 4 (November 6, 2007)

Langefors, B.: Theoretical Analysis of Information Systems, Studentlitterature (1966)

Langefors, B., Dahlbom, B. (ed.) Essays on Infology, Studentlitteratur, Lund (1995)

Maturana, H.R., Varela, F.J.: Autopoiesis and cognition. D. Reidel Publishing Company, Dordrecht (1980)

Midgeley, G.: Systems Thinking. Sage, Thousand Oaks (2003)

Mumford, E.: The story of socio-technical design. Information Systems Journal 16(4), 317 (2006)

Orlowski, A.: Why Nokia failed: Wasted 2000 man years' on UIs that didn't work. The Register, Mobile (March 10, 2011)

Samuelson, P.A., Nordhaus, W.D.: Economics, 19th edn. McGraw-Hill, New York (2009)

Schoderbek, P.P., Schoderbek, C.G., Kefalas, A.G.: Management Systems: conceptual Considerations, 4th edn (1990), Richard D. Irwin

Williams, P.: Make sure you get a positive return. Computer Weekly (November 13, 2007) 